\title{
Electrocardiographic Findings in Children with Spinal Muscular Atrophy
}

\author{
Joh-Jong Huang, MD, MS, Yuh-Jyh Jong, ${ }^{*}$ MD, MS, \\ Ming-Yii Huang, ${ }^{* *} \mathrm{MD}$, Chi-Hsiun Chiang, ${ }^{*} \mathrm{MD}, \mathrm{PhD}$, \\ and Teh-Yang HUANG, ${ }^{*} \mathrm{MD}, \mathrm{PhD}$
}

\begin{abstract}
SUMmary
Most of the patients in this study with spinal muscular atrophy were found to have tremors of the isoelectric line in the electrocardiogram (ECG) tracings. There were a total of 47 cases of SMA (mean age 40.8 months). All three types of SMA had a similar incidence (about $80 \%$ ) of tremors in the tracings $(p=0.885)$. In 7 cases the ECG tremors had an intermittent pattern. ECG tremors were commonly found in the majority of SMA patients and this finding, though non-specific, may suggest a possible SMA diagnosis. (Jpn Heart J 1996; 37: 239-242)
\end{abstract}

Key words: Electrocardiogram Spinal muscular atrophy Child

C PINAL muscular atrophies (SMA) are degenerative diseases with progressive $N$ loss of the alpha motor neuron of the spinal cord. ${ }^{1)}$ The incidence of SMA is estimated to be about $5-10 / 100,000$ births, mainly with an autosomal rccessive inheritance. ${ }^{2)}$ Three types of SMA with different degrees of severity were recognized as type 1 (scvcre), type 2 (intermediate), and type 3 (mild) according to the different level of motor function they achieved. . $^{3)}$ Although all 3 types present with weakness, the clinical presentation of the milder forms may be quite similar to that of patients with myopathies. ${ }^{4}$ In the past, it has been reported that tremors recorded on the electrocardiogram (ECG) might be a common finding of SMA, although with some inconsistency. ${ }^{5-7)}$ We have reviewed the ECG findings of patients with SMA to evaluate the presentation of the ECG tremors.

\section{Materials and Methods}

The ECG records of forty-seven children who were diagnosed as having SMA were used. Age ranged from 2 months to 13 years 11 months (mean

\footnotetext{
From the Department of Family Medicine, *Department of Pediatrics, and **Department of Radiotherapy, Kaohsiung Medical College, Kaohsiung City, Taiwan.

Address for correspondence: Teh-Yang Huang, MD, PhD, Department of Pediatrics, Kaohsiung Medical College, No. 100, Shih-Chuan 1st Road, Kaohsiung City 807, Taiwan.

Received for publication November 24, 1995.

Accepted December 25, 1995.
} 
40.8 \pm 39.2 months). All cases were examined in the nonsedated state. The ECGs were performed at a standard speed of $25 \mathrm{~mm}$ per second with $0.1 \mathrm{mV}$ per mm of height as the ordinary voltage calibration. ECGs were measured using an FK12 electrocardiogram (Fukuda Denshi Co., Tokyo). The tremors of the isoelectric line in the routine electrocardiogram were given special attention.

The SMA patients were divided into the three clinical categories as follows: type 1 (severe SMA, Werdnig-Hoffmann disease); type 2 (intermediate or chronic Werdnig-Hoffmann disease); type 3 (late-onset juvenile SMA, KugelbergWelander disease). ${ }^{3,8)}$

The chi square test was used to compare the incidence of ECG tremors among the three categories of SMA.

\section{Results}

Forty-seven cases were included in the study (Table I). The sex ratio was 2: 1 , with males predominating. The mean age was $40.8 \pm 39.2$ months. There were 7 type 1 cases with a sex ratio of $6: 1$ and mean age of $6.7 \pm 7.5$ months; 27 type 2 cases with a sex ratio of $1.7: 1$ and mean age of $39.8 \pm 36.1$ months; and 13 type 3 cases with a sex ratio of $1.6: 1$ and mean age of $61.4 \pm 43.4$ months.

Table I. Electrocardiological Findings in 3 SMA Subtypes

\begin{tabular}{|c|c|c|c|c|c|c|}
\hline \multirow{2}{*}{$\begin{array}{l}\text { SMA } \\
\text { type }\end{array}$} & \multirow{2}{*}{$\begin{array}{l}\text { Number of } \\
\text { cases }\end{array}$} & \multirow{2}{*}{$\begin{array}{c}\text { Age } \\
\text { (months) }\end{array}$} & \multirow{2}{*}{$\begin{array}{c}\text { Sex ratio } \\
\text { (Male: Female) }\end{array}$} & \multicolumn{3}{|c|}{ ECG Tremors } \\
\hline & & & & $\underset{(\%)}{\text { Continuous }}$ & $\begin{array}{c}\text { Intermittent } \\
(\%)\end{array}$ & $\begin{array}{c}\text { Absent } \\
(\%)\end{array}$ \\
\hline 1 & 7 & $6.7 \pm 7.5$ & $6: 1$ & $6(85.7)$ & $0(0)$ & $1(14.3)$ \\
\hline 2 & 27 & $39.8+3.61$ & 1.7: 1 & $16(59.3)$ & $6(22.2)$ & $5(18.5)$ \\
\hline 3 & 13 & $61.4+43.4$ & $1.6: 1$ & $9(69.2)$ & $1(7.8)$ & $3(23.1)$ \\
\hline Total & 47 & $40.8 \pm 39.2$ & 2: 1 & $31(66.0)$ & $7(14.9)$ & $9(19.1)$ \\
\hline
\end{tabular}
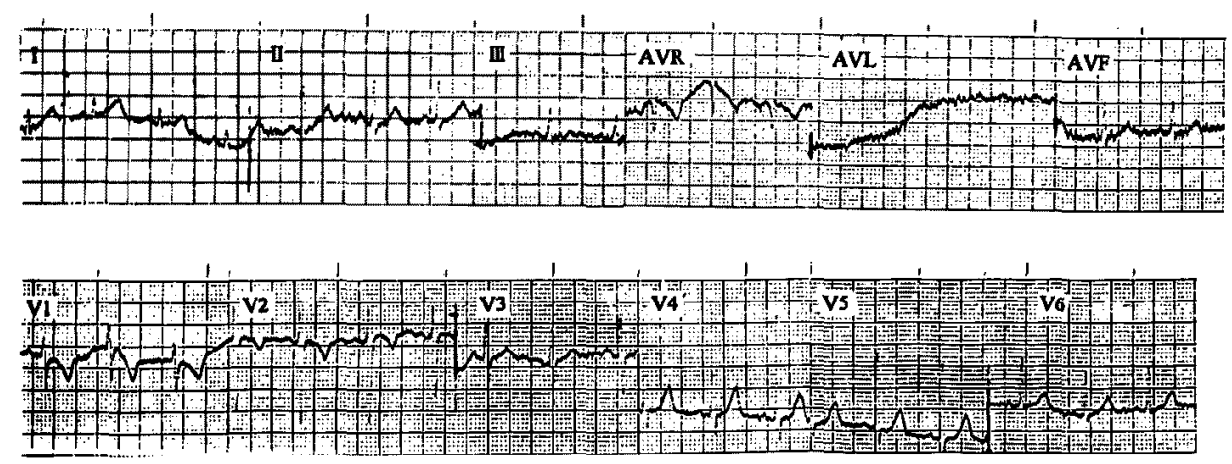

Figure 1. Tremors in the 12 ECG leads of a SMA type III patient. 
Table 2. Incidence of Electrocardiographic Tremors in SMA Patients

\begin{tabular}{|c|c|c|c|c|c|c|}
\hline & \multirow{2}{*}{ Year } & \multirow{2}{*}{$\begin{array}{c}\text { Number } \\
\text { of } \\
\text { cases }\end{array}$} & \multicolumn{4}{|c|}{ ECG Tremors in SMA } \\
\hline & & & Type $1(\%)$ & Type $2(\%)$ & Type $3(\%)$ & Total $(\%)$ \\
\hline Russman et $\mathbf{a l}^{5 /}$ & 1979 & 19 & NR & NR & NR & $19 / 19(100.0)$ \\
\hline Dawood et ${ }^{6}$ & 1983 & 31 & $2 / 10(20.0)$ & $8 / 10(80)$ & $9 / 11(81.8)$ & $19 / 31(61.3)$ \\
\hline Coletta et $\mathrm{al}^{7}{ }^{7}$ & 1989 & 13 & $3 / 3(100.0)$ & $8 / 8(100.0)$ & $1 / 2(50)$ & $12 / 13(92.3)$ \\
\hline This study & 1995 & 47 & $6 / 7(85.6)$ & $22 / 27(81.5)$ & $10 / 13(76.9)$ & $38 / 47(80.9)$ \\
\hline
\end{tabular}

$\mathrm{NR}=$ Not reported.

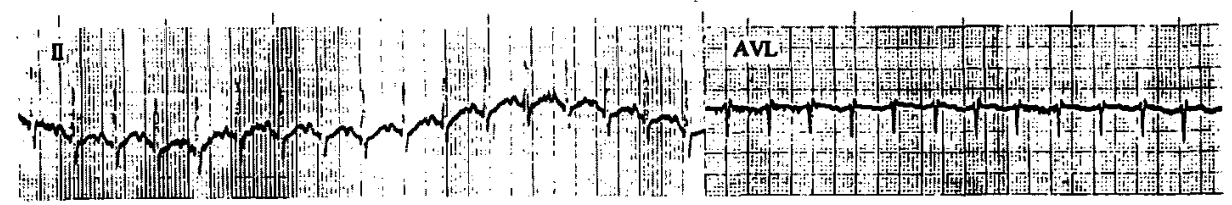

Figure 2. The intermittent pattern of tremors in lead II and AVL of the ECG of a SMA type I parient.

The pattern of ECG tremors is shown in Figure 1. This finding was noted in 38 cases $(80.9 \%)$. The remaining 9 cases had no evidence of tremors in their tracings. Tremors were observed in six type 1 cases $(85.7 \%)$, twenty-two type 2 cases $(81.5 \%)$ and ten type 3 cases $(76.9 \%$ ) (Table II). All three types of SMA had a similar incidence of EGG tremors $\left(x^{2}=0.243, p=0.885\right)$. Of the 38 cases with ECG tremors, all tremors were noted in limb leads. However, only twelve cases were found to have had tremors in precordial leads: one type 1, eight type 2 and three type 3.

Not all the tremors showed a continuous pattern in the tracings; there were 7 with an intermittent pattern: six type 2 and one type 3 (Figure 2). Most of these were found in limb leads. Only one case with an intermittent pattern was found to have tremors in both the limb and precordial leads.

\section{Discussion}

The most common, but non-specific, ECG finding of SMA patients in the study was the tremors, which were present in the tracings of most patients. All tracings with tremors were noted in the limb leads, with only some in the precordial leads. The origin of the tremors was postulated to be from the fasciculation of somatic muscles, which may be due to neuronal reinnervation activity during the course of degeneration of the alpha motor neurons. ${ }^{6,79-12)}$ The ECGs of patients who are anxious, cold or tense may show artifacts which are similar to ECG tremors. However, the incidence rate of those artifacts in the general population has been shown to be much lower than that of ECG tremors of SMA 
patients. $^{13)}$

There was no difference in the incidence of tremor in different SMA types. About $80 \%$ of the cases of each type had ECG tremors. ${ }^{5)}$ This finding was different from previous studies. Some reported that all or almost all patients had tremors; others reported that the majority of mild or intermediate type patients had the tremors, but they were uncommon in the severe type. ${ }^{6,7)}$ Nevertheless, all of these studies were with a small series with possible bias.

Not all the ECG tremors were present continuously in the tracings. The EGG tremors may group into clusters with no electric activity from the ECG isoelectric baseline between clusters of tremors (Figure 2). Some (7/38) showed this intermittent pattern. Most of the intermittent ECG tremors were noted in the limb leads. Only one case was noted in both the limb and precordial leads. This finding was not present in previous studies, and the mechanism and the meaning of the finding need further study.

Because the ECG tremors were noted in the majority of the SMA patients in this study, though non-specific, this phenomenon may suggest a possible SMA diagnosis.

\section{AGKNOWLEDGMENTS}

We thank Miss Chiung-Ping Ou for her kind help during this study.

\section{REFERENCES}

1. Dubowitz V. Muscle disorders in childhood. Philadelphia: Saunders, 1978: 146-78.

2. Emery AEH. Population frequencies of inherited neuromuscular diseases: A world survey. Neuromusc Dis 1991; 1: 19-29.

3. Munsat TL. Workshop report: International SMA collaboration. Neuromusc Dis 1991; $1: 81$.

4. Moosa A, Dubowitz V. Spinal muscular atrophy in childhood. Arch Dis Child 1973; 48: 386-8.

5. Russman BS, Fredericks EJ. Use of the EKG in the diagnosis of childhood spinal muscular atrophy. Arch Neurol 1979; 36: 317-8.

6. Dawood AA, Moosa A. Hand and EKG tremor in spinal muscular atrophy. Arch Dis 1983; 58: $376-$ 86.

7. Coletta C, Carboni P, Carunchio A. Electrocardiographic abnormalities in childhood spinal muscular atrophy. Int J Cardiol 1989; 24: 283-8.

8. Souidun S. Neuromuscular diseases. In: David RB editor. Pediatric Neurology for the Clinician. Norwalk: Appleton and Lange, 1992: 410-1.

9. Dubowitz V. Infantile muscular atrophy, a prospective study with particular reference to a slowly progressive variety. Brain 1964; 87: 707-12

10. Simpson JA, Thomaides T. Fasciculation and focal loss of nerve accommodation in peripheral neuropathies. Acta Neurol Scand 1988; 77: 133-41.

11. Swash M. Motor neuron disease. Postgrad Med J 1992; 68: 533-7.

12. Leigh PN, Ray-Ghaudhuri K. Motor nuron disease. J Neurol Neurosurg Psychiatry 1994; 57: 886-96.

13. Thomas DJ, Williams DO. Detcction of somatic muscle fasciculation on electrocardiograms. Br Med J 1976 ; i: $557-9$. 